\title{
Microalgae Zero Energy Farm for Bio fuel Production in Galicia
}

\author{
Á. López Agüera ${ }^{1}$, M. Vázquez García $^{1}$, V. Gándara Villadóniga ${ }^{1}$ and I. Rodríguez Cabo ${ }^{1}$ \\ ${ }^{1}$ Sustainable Energetic Applications Group. Department of Particle Physics \& Galician Institute of High Energy Physics. South Campus \\ 15702 Santiago de Compostela (Spain). Phone: +34 981 563100, fax: +34 981521091 ext.: 13974, \\ E-mail: a.lopez.aguera@usc.es, v.garcia.miguel@gmail.com
}

\begin{abstract}
Microalgae are the fuel source in the future. Galicia has excellent conditions for microalgae farm installations. A high efficiency in production process establishes a biodiesel production rate of $121 / \mathrm{m}^{2}$. Other sub products like hydrogen; biogas... will be used for factory energy saving for a zero energy design.
\end{abstract}

Experimental works will establish the basis for a high production algae farm design for biodiesel and derivatives bio fuels for local markets

\section{Key words}

Microalgae, Sustainable Energy, Bio fuels, Biodiesel, Hydrogen.

\section{Introduction}

It's possible to say that global economy runs on energy. An economic growth combined with a rising population has led to a steady increase in the global energy demand.

Transport is one of the fastest growing sectors using 27\% of energy. The continued use of fossil fuels is not sustainable, as they are finite resources and their combustion will lead to increased emission of greenhouse gases (GHG)

Research turns to search new types of fuel that supply fossil fuels and reduce contamination like bio fuels in their multiple generations [1].

The harvest and production of microalgae for the elaboration of bio fuel for multiple uses works already, in phase of study and tests, in different projects in Spain and other countries around the world obtaining satisfactory results.

This paper lays the basis for the installation of an experimental factory in Galicia. The main aim is evaluating both algae and microalgae for obtain high yields in bio fuel production potential in Galicia.
Galicia is the Spanish community with major contamination index for habitant and it's due to a high concentration of contaminant factories.

The differential fact of the project is double: The production and drying process will be sustainable (energy zero factory) and the bio fuel production will be diversified. The crossed exploitation ensures the highest efficiency.

The main routes for algae bio fuel transformation of the transformation like biodiesel, hydrogen, methanol and biogas are explored.

\section{Previous experimental works.}

The first phase will be to design and reproduce in laboratory systems for harvest algae in ideal conditions for the region of study.

Scaled photo bioreactors and open ponds will be used for small scale production in laboratory (Figure 1) to determinate harvesting conditions like ambient and water temperature, artificial lighting and nutrients needs for Galician algae.

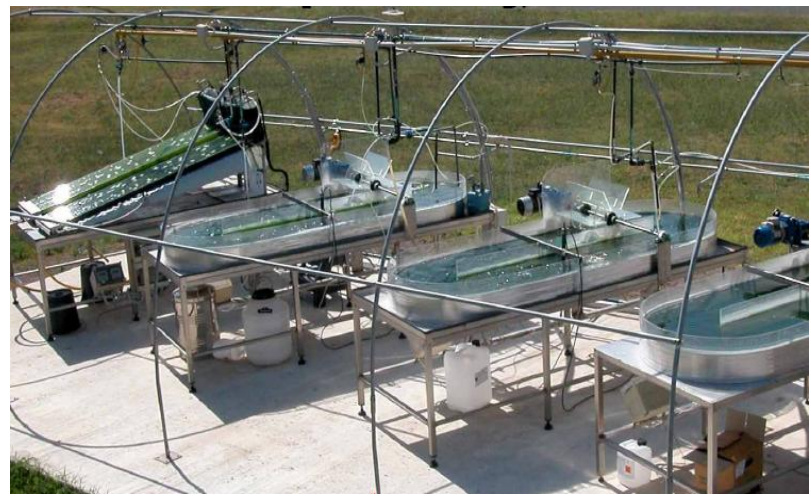

Fig. 1. Adapted indoor-outdoor open pond laboratory devices examples.

Major technical hurdles in design process are:

\section{A. Algae selection and bioreactor design}


Algae selection conditions will be:
1) Fast growth
2) High contents of lipids
3) Large cells size
4) Quick sedimentation

Optimal Galician algae will be determined in studies. His characteristics will be similar to species like Nannochloris, Spirulina and Chlorella or Diatomea Marina.

Photo bioreactors (Figure 2) are transparent pipes where nutrients are injected and algae are cultivated in small areas with a high efficiency and high costs.

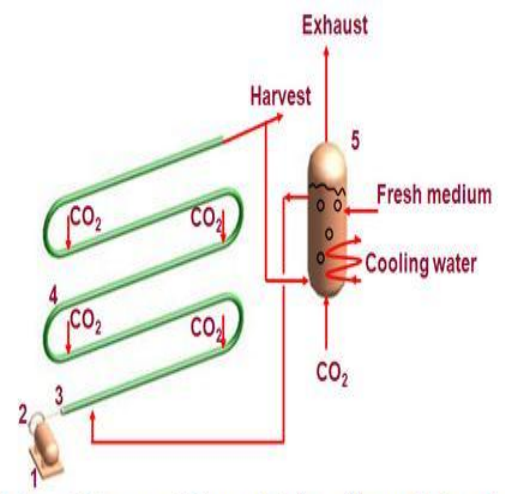

Note:1 Motor 2 Eccenter 3 Piston 4 Solar collector 5 Degassing column

Fig. 2. Photo bioreactor scheme

Open ponds are "raceway" design (Figure 3) consisting in a semi buried liner. A motorized paddle is used to shake harvesting medium (algae, water and nutrients mix). They will be proved in outdoor and indoor conditions to determine the maximum efficiency conditions.

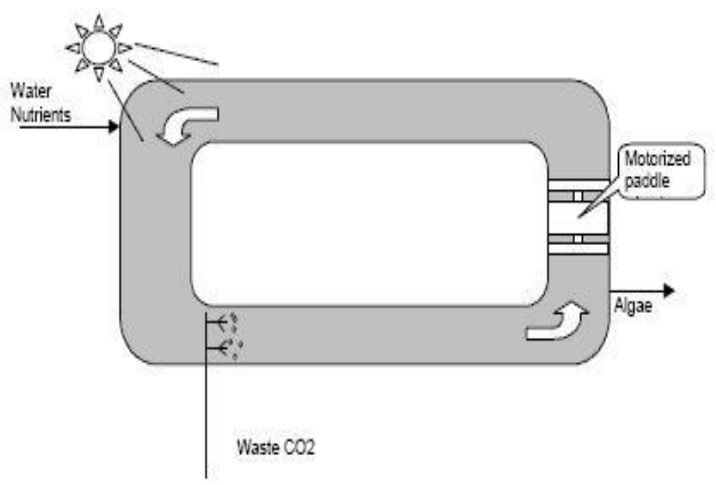

Fig. 3. Algae harvesting raceway (open pond)

\section{B. Optimal lighting (artificial light like a complement for natural light)}

Devices have to be adapted to daily, seasonal and regional solar radiation and climate to stimulate algae growth.

They have to ensure uniform light and avoid photoinhibition in summer light
Solutions are a complementation of natural light with an artificial lighting system. Low consumption and "solar spectrum" illumination systems are ideals to install on devices. Highly efficient lighting systems like LEDs will be proved in laboratory simulation systems.

Optimal lighting may result in $2-3 \mathrm{X}$ production increase

\section{Harvesting and oil production process}

Harvesting aims are:

1) Continuous production and harvesting cycle

2) Low cost oil extraction from biomass with a high lipid extraction rate and a fuel-grade quality output

\section{Scaling-up to industrial plants}

Scaling-up to industrial size plant needs high lab quality and yield performance and good process monitoring and control systems.

\section{Bio fuel farm.}

Ideal location to high scale algae production farm will be in the coast, to take sea water to harvesting processes and near high $\mathrm{CO}_{2}$ emissions factory and a good illumination zone, without shades. These two conditions establish a perfect way of culture [2].

First experimental Galician algae farm will consist in a $4.000 \mathrm{~m}^{2}$ area. $2.000 \mathrm{~m}^{2}$ will consists in an industrial building for indoor harvesting in artificial controlled conditions. There will be installed too the project laboratory for investigations.

Remaining area will be dedicated to outdoor cultures in natural conditions and for auxiliary systems.

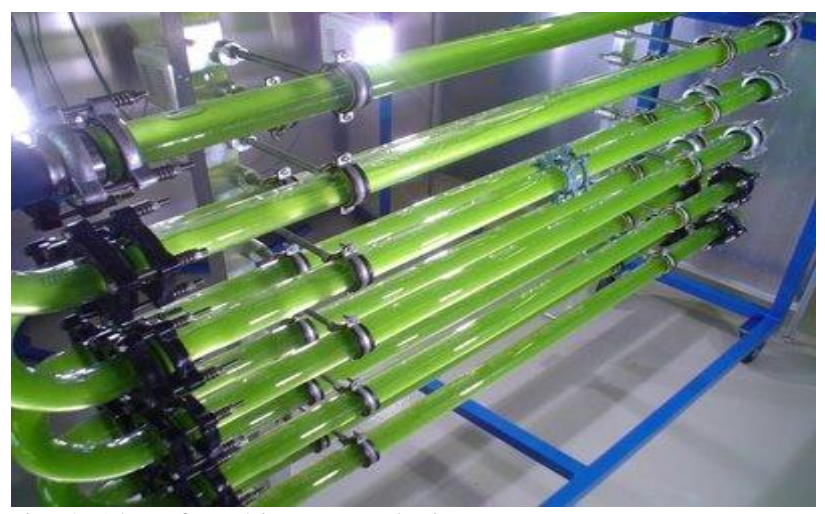

Fig. 4. Algae farm bio reactor device.

The capacity of production is estimated in 26.000 litres in $2000 \mathrm{~m}^{2}$. Waste from bio fuel microalgae process will be used to other bio fuel utilities like methanol (waste fermentation) or biogas production (anaerobic bacteria digestion).

Methanol is part of the process of biodiesel production with the oil extracted from microalgae biomass. 
The biogas obtained will be turned into electricity and this will be used to offset power requirements of the algae farm.

It will be designed like a closed cycle factory (figure 5) where all products and waste are used in the own factory.

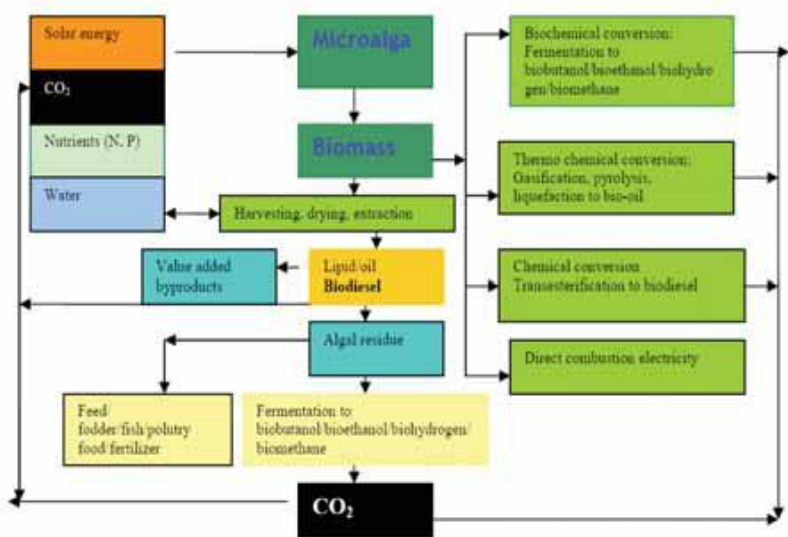

Fig. 5. Conceptual system for microalgae production

The differential fact of the project is double: The production and drying process will be sustainable (energy zero factory) and the bio fuel production will be diversified. The crossed exploitation ensures the highest efficiency.

For the objective of an energy zero factory, the farm will have some types of renewable systems: for warm water solar panels and a biomass boiler to burn waste from microalgae and photovoltaic for electricity contributions

\section{Future works.}

Complementary R\&D projects like hydrogen production and biodiesel from fish waste will be developed in the future.

\section{A. Hydrogen from microalgae}

Perhaps hydrogen could be the most important bio fuel in the future. It doesn't produce $\mathrm{CO}_{2}$ emissions and it has a direct conversion to electric energy into fuel cells.

The possible production way presented for study is called "Anaerobic production". Certain algae in conditions of low or null concentration of oxygen, produces $\mathrm{H}_{2}$ from dissociation of water molecules [3].

It's needed natural lighting or similar to photosynthesis processes in algae. So our design will have in mind these considerations.

Modifications will be made in experimental harvesting systems and then these modifications will be applied to microalgae farm culturing systems.

Existing culture devices will be transformed in closed ponds (covered ponds) and photo bioreactors with oxygen and hydrogen extraction systems (Figure 6)

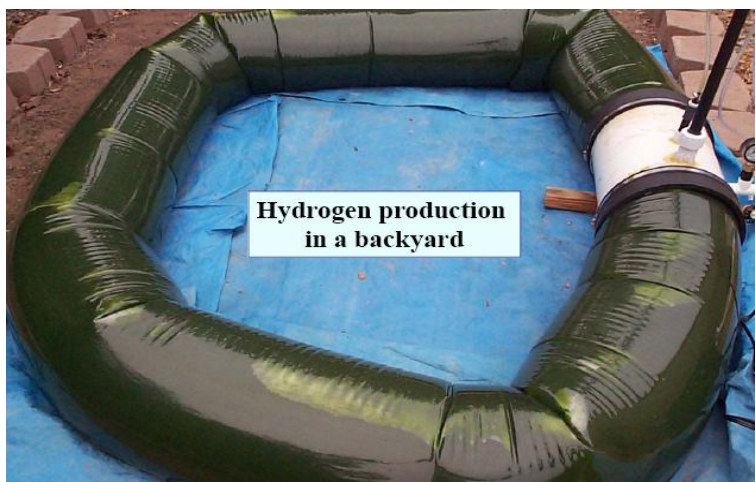

Fig.6. Hydrogen production device example.

\section{B. Fish waste biodiesel}

Fish waste from transformation industry will be also explored as oil source for biodiesel production [4].

Animal oil is too used to the production of biodiesel but it isn't most appropriate for biodiesel applications due to their high density and low fluency. Fish oil doesn't present this disadvantages and it makes it useful for biodiesel production together microalgae bio fuel.

The associated advantage is legated to the decrease of the contamination produced in the fishing coast by the slaughter waste, the use of resources not used until now.

These new research ways have the same initial idea of closed cycle and energy zero factory.

\section{Conclusion}

A diversified algae zero energy farm will be designed and prototyped in order to optimise the bio fuel production. Neighbours fishing coast waste will be explore as potential bio fuel complementary source.

Ambient advantages are the reduction of the emission of $\mathrm{CO}_{2}$ and other GHG legated to the use of clean fuels sources. Moreover, economic development of the zone will be expected with the creation of diverse working places and associated service small industries.

The propose project will be pioneer in Galicia.

\section{References}

[1] J. Sheehan, T. Dunahay; "A Look Back at the U.S. Department of Energy's Aquatic Species Program-Biodiesel from Algae" National Renewable Energy Laboratory.

[2] P. K. Campbell, T. Beer, "Greenhouse gas sequestration by algae - Energy and greenhouse gas life cycle Studies"

[3] T. Melis, T Happe. "Hydrogen Production. Green Algae as a Source of Energy"

[4] "Diesel from fish waste, bio fuel from algae" Eurofish Magazine 1 / 2009 